\title{
Congenital Pulmonary Airway Malformation (CPAM): A Case Report
}

\author{
TASLIM UDDIN AHMED ${ }^{1}$, SUDIPTA ROY ${ }^{2}$, ARM LUTHFUL KABIR ${ }^{1}$, KONA CHOWDHURY $^{3}$, MAHMUDA \\ HASSAN ${ }^{1}$, MD. ABID HOSSAIN MOLLAH ${ }^{4}$, RUBAIYA NOUSHIN ${ }^{5}$, MOHAMMAD ABDUR RAZZAQUE ${ }^{6}$, \\ RAIHANANOOR KHAN ${ }^{7}$, MD. HAMIDUR RAHMAN ${ }^{8}$
}

\begin{abstract}
Congenital pulmonary airway malformation (CPAM) is a very rare congenital cystic lung disease in children. Frequent respiratory tract infections (RTI) are major concerns in these patients. When a child having recurrent episodis of RTI, CPAM could be the underlying pathology. Surgical excision is recommended to make a definite diagnosis and exclude hidden malignancies and is also the treatment of choice. Here in, we report a 6 months old girl presenting with an acute respiratory infection for the first time. An routine USG of abdomen incidentally showed multiple cystic lessions in the left lower lung. CT scan of chest also revealed similar lessions in some area. After receiving treatment for pneumonia surgical excision was performed and she was doing well after surgery.
\end{abstract}

Key words: Pulmonary Airway Malformation, Multiple Cysts, Surgical Resection.

\section{Introduction}

Congenital pulmonary airway malformation (CPAM) is a rare congenital abnormality that presents in $0.004 \%$ of all pregnancies, and constitutes $<25 \%$ of all congenital pulmonary anomalies. ${ }^{1}$ About $15 \%-50 \%$ of cases of congenital cystic lung disease are reported to be CPAM. ${ }^{2}$ Congenital cystic adenomatoid malformation (CCAM) was first described by Ch'in and Tang in $1949^{3}$ and is now also known as CPAM due to the new classification system established by Stocker et al. ${ }^{4}$ There are five types of CPAM. ${ }^{4}$ CPAM is a rare congenital lung lesion with an estimated incidence $1: 25,000$ to $1: 35,000$ live births. The mortality rate is high with $12.5 \%$ death rate in newborn. ${ }^{5}$ CPAM are not associated with race, age, maternal exposure to any given factor or genetic factor. ${ }^{6}$ It occurs equally across races and gender. ${ }^{7}$ Typically, it is diagnosed on prenatal ultrasound, ${ }^{8}$ however, in the literature, it is also infrequentlv diagnosed in children and even less commonly in adults. ${ }^{1}$ More than $90 \%$ of these cases

1. Professor, Department of Pediatrics, Ad-din Women's Medical College (AWMC), Dhaka.

2. Assistant Professor, Department of Pediatrics, AWMC, Dhaka.

3. Associate Professor, Department of Pediatrics, ADWMC, Dhaka.

4. Professor and Head, Department of Paediatrics, Ibrahim Medial College, Dhaka

5. Honorary Medical Officer, Department of Pediatrics, AWMC, Dhaka.

6. Senior Specialist Paediatrician/Neonatologist, King Fahd Central Hospital Jizan, KSA

7. Assistant Professor, Dept. of Ultrasonography, ADWMC, Dhaka.

8. Professor and Head, Department of Pediatrics, ADWMC, Dhaka.

Correspondence: Dr. Sudipta Roy, Assistant Professor,

Department of Pediatrics, Ad-din Women's Medical College, Dhaka.

E-mail : sudipta.paediatrics@gmail.com

Received: 09 July, 2017

Accepted: 27 July, 2017 have been reported to be diagnosed in the first two years of life. This malformation can spontaneously regress, increase in size or cause non-immune hydrops fetalis. ${ }^{9}$ Its usual postnatal presentation is respiratory distress in the newborn period. This may be due tolpulmonary hypoplasia, mediastinal shift, spontaneous pneumothorax, and pleural effusions secondary to hydrops. Recurrent chest infections may be a feature later in life. ${ }^{10}$ The most common presentation in adults is recurrent and resistant infections. However, some of these lesions are also found incidentally on chest imaging in asymptomatic patients. Other common presentations include pneumothorax, dyspnoea and haemoptysis. ${ }^{1}$

\section{Case Summary:}

A 6 month old baby girl was admitted to our paediatric ward of AWMC suffering from intermittent nonproductive cough for 15 days, high grade intermittent fever along with respiratory distress for 2 days in association with loose mucoid stool and occasional vomiting for same duration. She was born after an uneventful 37 weeks of gestation. Her birth body weight was $3500 \mathrm{gm}$. Prenatal ultrasonography and postnatal physical examination revealed no abnormalities. Mother did not give $\mathrm{H} / \mathrm{O}$ previous hospitalization for any region after birth before this illness. She was the only issue of non consanguineous parents. Mother had no previous miscarriage or abortion and there was no family history of lung disease or malignancy. 
On admission, the child was dyspneic and irritable having intercostal and subcostal recession. She had fever of $102^{\circ} \mathrm{F}$, tachypnea with respiratory rate $80 /$ min, tachycardia with heart rate $134 / \mathrm{min}$. Her Weight (W) $8.4 \mathrm{Kg}$, Length (L) $66 \mathrm{~cm}$, Occipitofrontal Circumference (OFC) $42 \mathrm{~cm}$-on 50th centile, W/L on 75th centile, L/A on 90th centile with age appropriate milestones of development. Breath sound was slightly diminished over left lower lung field with few crackles. Her initial investigations revealed total leukocyte count ( TLC) $26,000 / \mathrm{cmm}$, neutrophil (N) $60 \%$, erythrocyte sedimentation rate $(E S R) 59 \mathrm{~mm} / \mathrm{hr}$, C-Reactive

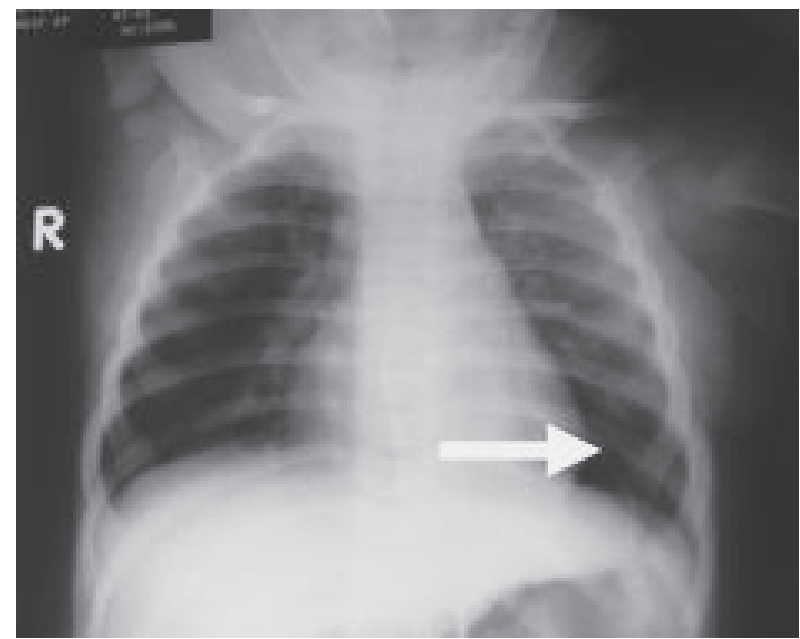

Fig:1 Normal chest $x$-ray except some increased translucency at left cardiophrenic region.

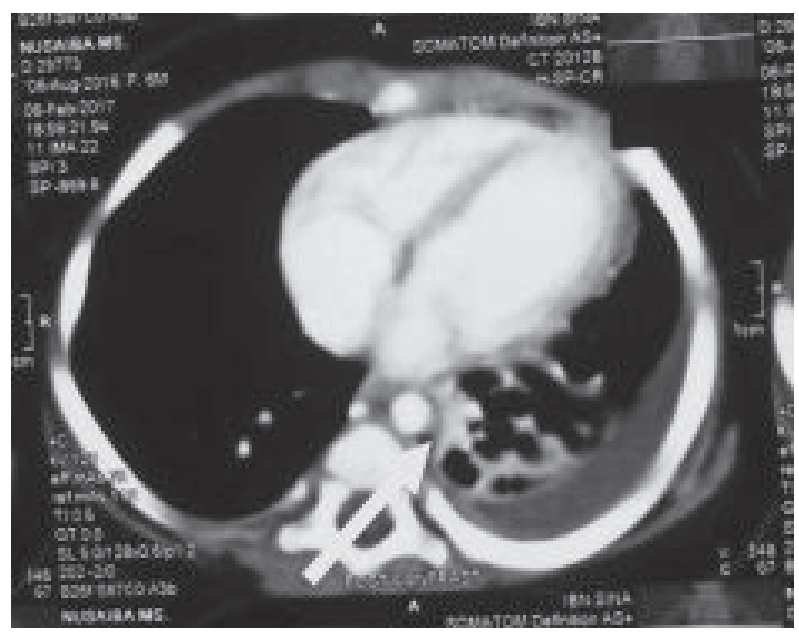

Fig.-2: Computed tomography of the chest demonstrating multiple small sized cystic areas in apical, posterior basal, and lateral basal segments of left lower lobe with small apico-posterior basal segment consolidation with mild pleural effusion. Volume of left lung is reduced with slight shifting of mediastinum to the left . Right lung is normal.
Protein ( CRP) $334 \mathrm{mg} / \mathrm{L}$. Chest X Ray (CXR) findings was normal except some increased translucency at left cardiophrenic region. An echocardiogram was performed to exclude cardiac anomalies that revealed Patent Foramen Ovale (PFO). Blood and urine culture showed no growth. Septicaemia with PFO was then considered. She was given Inj. Ceftriaxon in addition to other symptomatic and supportive treatment. For persistent irritability, continuous crying and gastrointestinal tract symptoms an ultrasonography (USG) of abdomen was performed that incidentally revealed $7.4 \times 4.3 \mathrm{~cm}$ sized echogenic area with multiple cystic and hypoechoic lesions seen in the left pleural space adjacent to the heart. This findings directed us to perform a Computed tomography (CT)

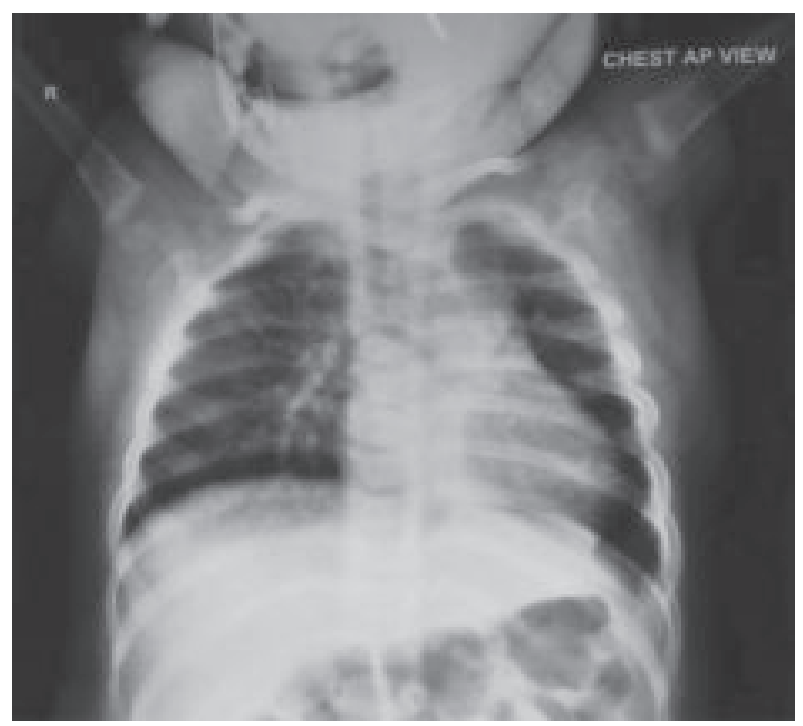

Fig.-3: Follow-up chest $x$-ray one month after surgery

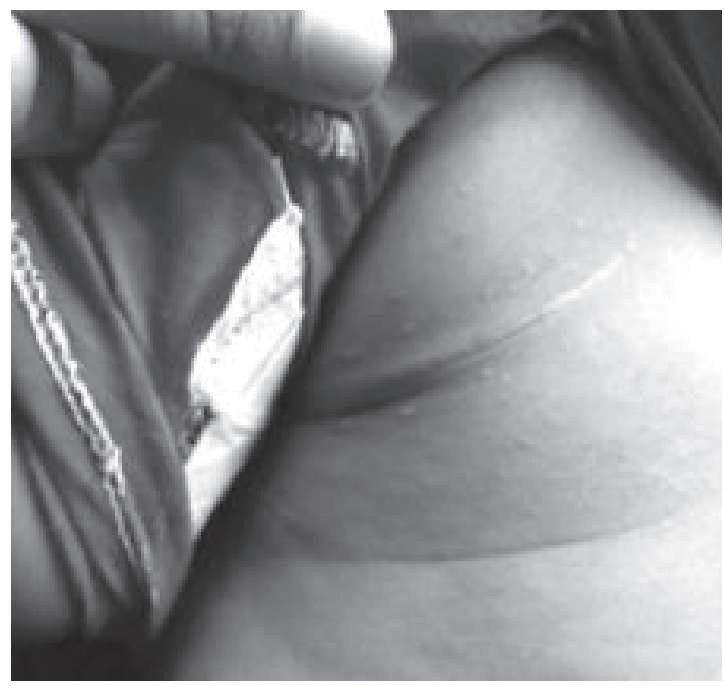

Fig.-4: Post surgical incision mark 


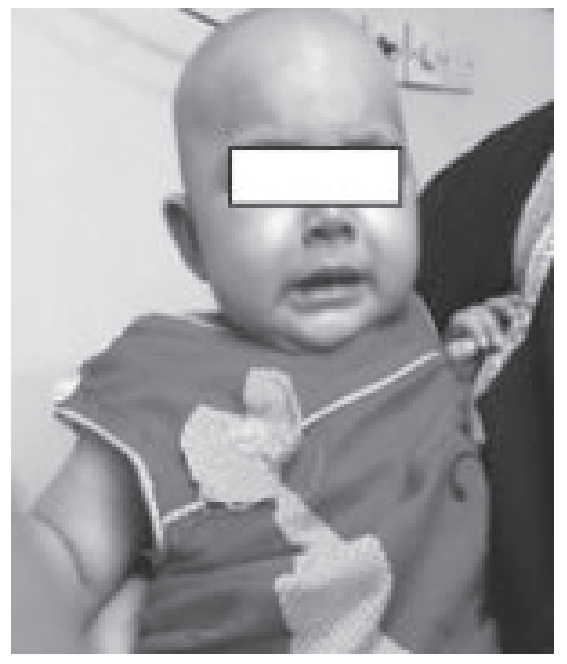

Fig.-5: The child 2 months after surgery

scan of Chest that showed multiple small sized cystic areas in apical, posterior basal and lateral basal segments of left lower lobe. Small air space solid lesion is seen in apical and basal segments of lower lobe with slight shifting of mediastinum to left - suggestive of type II congenital pulmonary airway malformation of left lower lobe of lung with small consolidation of left lower lobe with left sided pleural effusion. So our final diagnosis was Congenital pulmonary airway malformation (CPAM) with pneumonic consolidation. The girl became afebrile after 5 days of hospital stay. Respiratory distress and general condition improved gradually. A full course of antibiotic treatment was given. Then she was referred to thoracic surgeon for surgical resection. The baby underwent lobectomy and her postsurgical period was uneventful. After the surgery, baby is doing well for last 6 months without any major respiratory symptoms. Now she is developmentally age appropriate having normal growth. Presently, at the age of 1 year, her weight is $9.6 \mathrm{~kg}$, length $75 \mathrm{~cm}, \mathrm{~W} / \mathrm{H}$ on 50 th centile and $\mathrm{L} / \mathrm{A}$ on $75 \mathrm{th}$ centile, OFC $45 \mathrm{~cm}$ that falls on 50th centile.

\section{Discussion:}

Congenital cystic lung disease in children is rare with various clinical presentations. Pulmonary sequestration, congenital pulmonary airway malformation (CPAM), congenital lobar emphysema, and bronchogenic cysts are the four major congenital cystic lesions found in the lungs. ${ }^{11}$.Broncho-pulmonary sequestration (BPS) is a condition which closely mimics CPAM but is lung tissue with no bronchial connection. The non functioning lung may also result in mass effect similar to a CPAM. The difference between the lesions is that arterial supply to CPAM is from the pulmonary artery whereas BPS has a systemic vascular supply. ${ }^{12}$

The cause of CPAM is unknown. One theory holds that it is the result of bronchial structures failing to mature properly at the time the lungs begin to form the fifth or sixth week of gestation. Another theory suggests that CPAM is due to an abnormal growth pattern of lung tissue that occurs as a result of bronchial obstruction. ${ }^{4}$ Histologic studies reveal rapid vascular and epithelial growth within the tumor. Recent findings of accelerated cellular proliferation and decreased apoptosis within resected CPAM specimens further suggest a benign neoplastic development. ${ }^{13}$ There is no known genetic cause for CPAM, and no cases of recurrence in a sibling or offspring have been reported. Increased cell proliferation and decreased apoptosis may cause malignant transformation. Pleuropulmonary blastoma and bronchioloalveolar carcinoma in particular have been reported. ${ }^{4}$

Abnormal Hoxb-5 regulation causes specific alterations in airway branching. Normal lung tissue does not express significant levels of Hoxb-5 protein, while the adjacent CPAM with abnormal and immature airway express the high levels of Hoxb-5. The abnormal expression of this Hox gene could be associated with the development of aberrant branching patterns in BPS and CPAM . ${ }^{14}$ In infants and children, malformations communicate with the tracheobronchial tree, creating a valvular mechanism, which causes hyperinflation of the cystic zone during inspiration and less deflation during expiration. Enlarged cysts compressing the normal pulmonary structure lead to the respiratory symptoms. Glandular tissue proliferation may cause mucin accumulation and recurrent infections. CPAM is now preferred over CCAM since the lesions are cystic in only 3 of the 5 types of these lesions and adenomatoid in only one type. ${ }^{15}$

\section{Classification system for CPAM}

Based on embryological level of origin and histological features by Stocker et al. ${ }^{16}$

0 . Incidence $1-3 \%$. It is the rarest form and arises from trachea/bronchus. It involves the entire lungs. Cysts are small. Presentation is severe and lethal.

1. Commonest, representing $50-70 \%$ of all cases, arises from distal bronchus or proximal bronchiole. 
It shows multiple small number of large cysts, of size $2-10 \mathrm{~cm}$. A single dominant cyst may be seen. Cyst walls are thin, lined by ciliated pseudostratified epithelium. Other cell types like cartilage may be found between the cysts. Due to the large size, these CCAMs may cause significant mass effect, which may cause hydrops fetalis.

2. Constitute $15-30 \%$ of all cases, arises from the terminal bronchioles. They are composed of smaller cysts, of size $0.5-2 \mathrm{~cm}$, with solid areas which are difficult to differentiate from surrounding tissue. They are lined by ciliated columnar or cuboidal epithelium with elements of bronchioles or alveoli. Cysts are more evenly spaced than in type I. Associated abnormalities are seen in up to $60 \%$ cases including most organ systems. ${ }^{16}$ Type II lesions are often associated with other congenital malformations and the outcome depends on the severity of these anomalies. Common malformations associated with type II include renal agenesis and dysgenesis, cardiac anomalies tetralogy of Fallot, persistant truncus arteriosus, diaphragmatic hernia, small intestine anomalies jejunal atresia, skeletal anomalies. ${ }^{17}$ However, our case was consistent with Type-2 CPAM that was associated with patent foramen ovale (PFO).

3. They account for $5-10 \%$ of cases, arising from acinar type of tissue. They are composed of small cysts; hence the mass appears echogenic and solid on USG. The tissue is acinar with adenomatoid elements, arising from distal airways. Type 3 CPAM generally is unilateral .

4. They account for $5-15 \%$ of cases and are alveolar in origin with unlined cysts. They contain large cysts that may be as large as $10 \mathrm{~cm}$ and may be associated with malignancy, especially pleuropulmonary blastoma. ${ }^{16}$

Type 1, 2 and 4 usually involve only 1 lobe .Whole lung involvement can occur in type 0 and $3 .{ }^{18}$ Our case was Type-2 CPAM and it was confined only in left lower lobe. The prenatal rate of detection of lung cysts at the routine 18-20th week scan is almost $100 \%$ and may be the most common example of actual presentation. Late pregnancy diagnosis of CPAM is less sensitive. Once a cystic lung lesion is detected on ultrasound, the location, volume, size, macrocystic or microcystic classification, and blood supply should be evaluated. ${ }^{19}$ Serial prenatal sonographic examinations are important for helping to determine the prognosis and necessity for possible intrauterine treatment in patients with CPAM. The prognosis is highly variable and depends on the presence of fetal hydrops and fetal therapies such as needle aspiration, catheter shunt placement and fetal surgical resection can be applied. The majority of these lesions will regress or become normal echoic in late pregnancy. ${ }^{20}$ Ebru et al reported a case of nonimmune hydrops fetalis associated with CPAM Type 2 diagnosed on $19^{\text {th }}$ weeks of gestation during antenatal USG. ${ }^{21}$ But in this case mother was on regular antenatal check-up and USG was performed several times that did not reveal any abnormalities. Chitra et al. described steroids in selected cases may be an additional tool to delay or avoid fetal surgery by causing regression of the lesion. ${ }^{22}$ Postnatal spontaneous resolution of CPAM rarely has been reported. ${ }^{23}$ In some cases, the lesion appeared to shrink over time, while in others, the lesion spontaneously resolved. The cause of resolution of CPAM is not clear. John et al. described a case of type 4 CPAM who presented with spontaneous pneumothorax just after birth. Spontaneous resolution occurred, obviating the need for surgical intervention. ${ }^{24}$

CPAM has been associated with the presence of rhabdomyosarcoma, pleuropulmonary blastema and most commonly bronchioalveolar carcinoma (BAC) and adenocarcinoma of the lung..$^{25}$ Type 1 CPAM may involve malignant transformation of mucinous bronchioalveolar carcinoma ${ }^{26}$ and type 4 CPAM requires examination of the entire lesion to exclude pleuropulmonary blastoma. ${ }^{4}$ I-Ching et al. described case of CPAM type 4 without any malignant transformation in a 1yr old girl presented with localized pneumothorax . ${ }^{27}$ Suleyman et al. describe a threeday-old infant with respiratory distress and cystic lung lesion on her left lung. A lobectomy was performed at the age of three days, and the patient was diagnosed with congenital pulmonary airway malformation and adenocarcinoma in situ. ${ }^{25}$ One published case report that identified a 6 -year-old male with a type 1 CPAM and biopsy proven BAC. He was managed conservatively over a 15 year period and at age 21 he was diagnosed with metastatic adenocarcinoma. ${ }^{28}$ The vast majority of authors recommend surgical excision of these lesions for definitive treatment, due to the risk of malignant transformation and recurrent pulmonary infection. This recommendation remains controversial, as some authors argue that the risk of malignant transformation is over stated. ${ }^{29}$ Benjamin 
et al. described a patient who developed BAC at 19 years of age after resection. Therefore, it is recommended that patients with CPAM, even if resected should be followed closely for malignancy. ${ }^{30}$

The treatment of asymptomatic CPAM is defined less clearly. Observation may be a choice, but the patient and/or his family should be informed about both the possibility of infection and the low but definite risk of malignancy. If resection is advised in asymptomatic cases, then most surgeons would schedule surgery between the neonatal period and the first birthday. The lung continues to grow and develop until at least two years of age, and there is some suggestion that there is better catch-up lung growth following early thoracotomy. ${ }^{31}$

Limitation : Though we don't have pathological proof of the lesion reported here, we believe that it most likely represent a type 2 CPAM on the basis of clinical presentations, USG and CT scan of the chest reports and child's clinical well-being after surgery .

\section{Conclusion:}

CPAM is a rare pathology. Our case report documents a patient of 6 month old girl having pneumonia associated with CPAM Type 2 whose diagnosis was made incidentally. CPAM can present at any age and the clinical presentation vary from immediate postnatal respiratory failure to an accidental finding on chest radiography. Recurrent $\mathrm{RTI}$ and malignant transformation are the major concern of the undiagnosed patient. Surgical excision is recommended to make a definite diagnosis and rule out hidden malignancies. It is also the treatment of choice.

\section{References:}

1. McDonough RJ, Niven AS, Havenstrite KA. Congenital pulmonary airway malformation: a case report and review of the literature. Respir Care 2012;57:302-6 .

2. Chan C, Lee YS, Taso PC, Jeng MJ, Soong WJ. Congenital Pulmonary Airway Malformation Type IV: A case report. Journal compilation 2013. Available from: URL: http://www.pedipulm.org.tw/ ezcatfiles/rb02/img/img/231/9-2.6.48.pdf

3. Ch'In KY, Tang MY. Congenital adenomatoid malformation of one lobe of a lung with general anasarca. Arch Pathol. 1949;48:221-229.

4. Stocker JT. Cystic lung disease in infants and children. Fetal Pediatr Pathol. 2009;28:155-184.
5. Laberge JM, Flageole H, Pugash D. Outcome of the prenatally diagnosed congenital cystic adenomatoid lung malformation: a Canadian experience. Fetal Diagn Ther 2001; 6:178-186.

6. Herrero Y, Pinilla I, Torres I. Cystic adenomatoid malformation of the lung presenting in adulthood. Ann Thorac Surg 2005; 79:326-9.

7. Hellmuth D, Glerant JC, Sevestre H. Pulmonary adenomatoid malformation presenting as unilobar cysts in an adult. Respir Med. 1998;92:1364-7.

8. Joachimescu OC, Mehta AC. From cystic pulmonary airway malformation, to bronchioloalveolar carcinoma and adenocarcinoma of the lung. Eur Respir J. 2005;26:1181-7.

9. Janka GE, Schneider EM. Modern management of children with hemophagocytic Iymphohistiocytosis .Br J Hematol. 2004; 124:4-14 .

10. Luján M, Bosque M, Mirapeix RM, Marco MT, Asensio O, Domingo C. Late-onset congenital cystic adenomatoid malformation of the lung. Embryology, clinical symptomatology, diagnostic procedures, therapeutic approach and clinical follow-up. Respiration. 2002;69(2):148-54.

11. Takeda S, Miyoshi S, Ino Stocker JT. Cystic lung disease in infants and children. Fetal Pediatr Pathol. 2009;28:155-84.

12. Crombleholme TM, Coleman B, Hedrick $\mathrm{H}$. Cysticadenomatoid malformation volume ratio predicts outcome in prenatally diagnosed cystic adenomatoid malformation of the lung. J Ped Surg, Volume 37, Issue 3, March 2002, Pages 331-338, doi:10.1053/jpsu.2002.30832.

13. Wilson RD, Hedrick HL, Liechty KW, Flake AW, Johnson MP, Bebbington M, et al. Cystic adenomatoid malformation of the lung: review of genetics, prenatal diagnosis, and in utero treatment. Am J Med Genet A. 2006;140(2): 151-5.

14. Volpe MV, Pham L, Lessin M, Ralston SJ, Bhan I, Cutz E, Nielsen HC. Expression of Hoxb-5 during human lung development and in congenital lung malformations. Birth Defects Res A Clin Mol Teratol. 2003; 67:550-6.

15. Oh BJ, Lee JS, Kim JS, Lim CM, Koh Y. Congenital cystic adenomatoid malformation of the lung in adults: clinical and CT evaluation of seven patients. Respirology 2006;11:496-501. 
16. Stocker JT, Madewell JE, Drake RM. Congenital cystic adenomatoid malformation of the lung. $A$ classification and morphologic spectrum . Hum Pathol 1977;8:155-171.

17. Davidson LA, Batman P, Fagan DG. Congenital acinar dysplasia: a rare cause of pulmonary hypoplasia. Histopathology. 1998;3:57-59.

18. Kao SW, Zuppan CW, Young LW. AIRP best cases in radiologic -pathologic correlation : type 2 congenital cystic adenomatoid malformation (type 2 congenital pulmonary airway malformation). Radiographics 2011;31: 743-8.

19. Mann S, Wilson RD, Bebbington MW, Adzick NS, Johnson MP. Antenatal diagnosis and management of congenital cystic adenomatoid malformation. Semin Fetal Neonatal Med. 2007; 12:477-81.

20. Chen HW, Hsu WM, Lu FL, Chen PC, Jeng SF, Peng SS, et al. Management of congenitalcystic adenomatoid malformation and bronchopulmonary sequestration in newborns. Pediatr Neonatol. 2010; 51:172-7.

21. Tastekin E, Usta U, Kaynar A, Ozdemir C ,Yalcin O , Ozyilmaz F, et al. Congenital Pulmonary Airway Malformation Type 2 : A case Report with Review of the Literature . Turk Patoloji Derg 2016 ; 32 :200-204.

22. Andrew C, Gopal S, Ramachandran H, Balakrishnan $U$, Vishwanath $U$. Congenital pulmonary airway malformation-hybrid lesion- a case report. Medplus- International Medical Journal September $2014 ; 1(9): 572-575$.

23. S.A. Butterworth and G.K. Blai. Postnatal Spontane-ous Resolution of Congenital Cystic Adenomatoid Mal-formations. Journal of Pediatric Surgery, Vol. 40, No. 5, 2005, pp. 832834. doi:10.1016/j.jpedsurg.2005.01.051
24. Amodio J, Perenyi A, Zember J, Smith M. PostNatal Spontaneous Resolution of a Congenital Pulmonary Airway Malformation in an Infant: Plain Radiographic and CT Manifestations. Open Journal of Medical Imaging.2012; 2:47-49.

25. Balkanli S, Ozturk MA, Kose M, Bastug O, Tekelioglu F, Hasdiraz L, et al. A report of adenocarcinoma in situ and congenital pulmonary airway malformation in athree-day-old infant with a review of the literature. Turl J Pediatr 2014; 56: 299-302.

26. Ramos SG, Barbosa GH, Tavora FR, Jeudy J, Torres LA, Tone LG, et al. Bronchioloalveolar carcinoma arising in a congenital pulmonary airway malformation in a child: case report with an update of this association. J Pediatr Surg. 2007; 42:E1-4.

27. Chan IC, Lee YS, Tsao PC, Jeng MJ, Soong WJ . Congenital Pulmonary Airway Malformation Type4: A Case Report.J Pediatr Resp Dis 2013; 9: 48- 52.

28. Loachimescu OC, Mehta AC. From cystic pulmonary airway malformation,to bronchioloalveolar carcinoma and adenocarcinoma of the lung. Eur Respir J 2005;26(6):1181-1187.

29. Fitzgerald DA. Congenital cyst adenomatoid malformations: resect some and observe all? Paediatr Respir Rev 2007;8(1):67-76.

30. Benjamin DR, Cahill JL. Bronchioloalveolar carcinoma of the lung and congenital cystic adenomatoid malformation. Am J Clin Pathol 1991; 95: 889-892.

31. Kotecha S, Barbato A, Bush A. Antenatal and postnatal management of congenital cystic adenomatoid malformation. Paediatr Respir Rev 2012; 13: 162-170. 